\title{
Metal Oxyhydroxide Dissolution as Promoted by Structurally Diverse Siderophores and Oxalate
}

by

Martin M. Akafia, ${ }^{1}$ James M. Harrington, ${ }^{1,2}$ John R. Bargar, ${ }^{3}$ and Owen W. Duckworth ${ }^{1, *}$

${ }^{1}$ Department of Soil Science, North Carolina State University, Raleigh, NC 276957619

${ }^{2}$ Current Address: Trace Inorganics Department, Technologies for Industry and the Environment, RTI International, Durham, NC 27709

${ }^{3}$ Chemistry and Catalysis Division, Stanford Synchrotron Radiation Lightsource, SLAC National Accelerator Laboratory, Menlo Park, CA 94025, USA

Submitted in revised form to Geochimica et Cosmochimica Acta June 17, 2014

*To Whom Correspondence Should be Addressed owen_duckworth@ncsu.edu

Tel. (919) 513-1577

Fax. (919) 515-1267 
Abstract. Siderophores, a class of biogenic ligands with high affinities for $\mathrm{Fe}(\mathrm{III})$, promote the dissolution of metal ions from sparingly soluble mineral phases. However, most geochemical studies have focused on quantifying the reactivity of DFOB, a model trishydroxamate siderophore. This study utilized three different siderophores, desferrioxamine B, rhizoferrin, and protochelin, with structures that contain the most commonly observed binding moieties of microbial siderophores to examine the siderophore-promoted dissolution rates of $\mathrm{FeOOH}$, $\mathrm{CoOOH}$, and $\mathrm{MnOOH}$ in the absence and presence of the ubiquitous low molecular mass organic acid oxalate by utilizing batch dissolution experiments at $\mathrm{pH}=5-9$. Metal-siderophore complex and total dissolved metal concentrations were monitored for durations of one hour to fourteen days, depending on the metal oxyhydroxide identity and solution $\mathrm{pH}$. The results demonstrate that $\mathrm{MnOOH}$ and $\mathrm{CoOOH}$ generally dissolve more quickly in the presence of siderophores than $\mathrm{FeOOH}$. Whereas $\mathrm{FeOOH}$ dissolved exclusively by a ligand-promoted dissolution mechanism, $\mathrm{MnOOH}$ and $\mathrm{CoOOH}$ dissolved predominantly by a reductive dissolution mechanism under most experimental conditions. For $\mathrm{FeOOH}$, siderophore-promoted dissolution rates trended with the stability constant of the corresponding aqueous Fe(III) complex. In the presence of oxalate, measured siderophore-promoted dissolution rates were found to increase, decrease, or remain unchanged as compared to the observed rates in single-ligand systems, depending on the $\mathrm{pH}$ of the system, the siderophore present, and the identity of the metal oxyhydroxide. Increases in observed dissolution rates in the presence of oxalate were generally greater for $\mathrm{FeOOH}$ than for $\mathrm{MnOOH}$ or $\mathrm{CoOOH}$. These results elucidate potential dissolution mechanisms of both ferric and non-ferric oxyhydroxide minerals by siderophores in the environment, and may provide further insights into the biological strategies of metal acquisition facilitated by coordinated exudation of low molecular weight organic acids and siderophores. 


\section{Introduction}

All organisms require transition metals, such as $\mathrm{Co}, \mathrm{Mn}$, and $\mathrm{Fe}$, for use in the metalloproteins and enzymes that are necessary for proper metabolic function (Frausto da Silva and Williams, 1991). Under oxic conditions at circumneutral $\mathrm{pH}$, these metals tend to be entrained in insoluble oxide and hydroxide minerals that are not readily available for biological uptake (Adriano, 2001). To overcome the potential limits on organism nutrition caused by the low bioavailability of iron and possibly other metals, graminaceous plants, bacteria, and fungi exude organic molecules, such as low molecular mass organic acids and siderophores, that promote the dissolution, solubilization, and uptake of nutrient metals (Kraemer, 2004; Marschner et al., 1986; Winkelmann, 2007).

Siderophores (derived from Greek meaning "iron carrier”) are specialized chelating agents exuded by microorganisms during periods of iron stress to enhance iron bioavailability. Currently, about 500 different types of siderophores have been discovered (Hider and Kong, 2010). Despite this structural diversity, microbial siderophores are typically characterized as tetra- or hexa-dentate ligands with oxygen-bearing moieties (commonly hydroxamate, catecholate, salicylate, $\alpha$-hydroxycarboxylate, or carboxylate) that directly bind a central metal ion [viz. Fe(III)] (Crumbliss and Harrington, 2009). These configurations result in thermodynamically stable, soluble complexes that can be taken up via specific cellular receptors (Harrington and Crumbliss, 2009; Stintzi et al., 2000). Although most geochemical studies to date have utilized the trishydroxamate siderophore desferrioxamine B (DFOB), it is reasonable to assume that siderophores may display a range of reactivity that will be largely dictated by the nature of the ligand moieties that interact directly with the metal center. 
An important proposed role of siderophores in soils is promoting the dissolution of iron from low solubility minerals. Desferrioxamine B promotes iron dissolution from a number of different phases, including oxides, hydroxides, phosphates, sulfides, and clay minerals (CerviniSilva et al., 2012; Cervini-Silva and Sposito, 2002; Cornejo-Garrido et al., 2008; Haack et al., 2008; Liermann et al., 2005; Liermann et al., 2000; Rosenberg and Maurice, 2003; Watteau and Berthelin, 1994; Wolff-Boenisch and Traina, 2007a). The DFOB-promoted dissolution of $\mathrm{FeOOH}$ has been shown to proceed by a surface-controlled mechanism, resulting in the formation of a Fe(III)HDFOB ${ }^{+}$complex (Cocozza et al., 2002). Interestingly, in the presence of DFOB and low molecular mass organic acids (such as oxalate), the dissolution rate of goethite is enhanced beyond a simple combination of the single-component dissolution rates (Cervini-Silva and Sposito, 2002; Cheah et al., 2003; Wolff-Boenisch and Traina, 2007b). This "synergistic" effect results from oxalate acting as an iron shuttle that delivers Fe(III) to dissolved siderophores, with rate of detachment of a labile pool of $\mathrm{Fe}(\mathrm{III})$-oxalate surface complexes enhanced by the presence of the siderophore (Loring et al., 2008; Reichard et al., 2007a; Reichard et al., 2007b).

Recent studies have suggested that siderophores may play diverse roles in the environment beyond promoting Fe(III) solubilization and uptake (Duckworth et al., 2009a; Duckworth et al., 2009b; Kraepiel et al., 2009; Schalk et al., 2011). Despite the assumed high specificity of siderophores for Fe(III), strong interactions between DFOB and other metals have been recognized for over 50 years (Anderegg et al., 1963). In fact, metal ions such as $\mathrm{Mn}(\mathrm{III})$ and $\mathrm{Co}(\mathrm{III})$ may have stability constants with siderophores that rival or exceed those of $\mathrm{Fe}$ (Duckworth et al., 2009b; Duckworth and Sposito, 2005a; Harrington et al., 2012a; Harrington et al., 2012b; Parker et al., 2004). Interestingly, in the small number of studies that have probed the siderophore-promoted dissolution rates of $\mathrm{Mn}$ - and Co-bearing minerals, both reductive and 
ligand-promoted dissolution mechanisms have been observed (Bi et al., 2010; Duckworth and Sposito, 2005b; Duckworth and Sposito, 2007; Peña et al., 2007). Whether a reductive or ligandpromoted dissolution mechanism predominates may be controlled by the electrode potential of the mineral (Bi et al., 2010).

The interactions between DFOB and Fe(III)-bearing minerals have been well studied, but only a limited number of studies exist that have explored mineral dissolution rates and mechanisms as promoted by other siderophores (Cervini-Silva, 2008; Dehner et al., 2010; Haack et al., 2008; Hersman et al., 1995; Reichard et al., 2005; Wolff-Boenisch and Traina, 2007b), a fact that limits our understanding of the function of siderophores in soils and natural waters (Kraemer, 2004). In addition, to our knowledge there have been no published studies that examine the interactions of siderophores other than DFOB with $\mathrm{Mn}$ (III) and Co(III)-bearing minerals. The goals of this study were to quantify and compare the dissolution rates of $\mathrm{FeOOH}$, $\mathrm{MnOOH}$, and $\mathrm{CoOOH}$ as promoted by several structurally diverse microbial siderophores, including DFOB, rhizoferrin, and protochelin (Fig. 1), in the absence and presence of oxalic acid. The results were then discussed in terms of the possible fate of siderophores in the environment and their role in the biological uptake of metals.

\section{Materials and Methods}

\subsection{Materials}

All solutions were prepared in ASTM Type I deionized water (DI; resistivity > $18 \mathrm{M} \Omega$ $\mathrm{cm})$. Unless otherwise noted, all chemicals were obtained from Fisher Scientific or VWR international and were of reagent or ACS certified grade. 
The three siderophores examined in this study, which were chosen for their structural diversity (Fig. 1), are all produced by soil-based bacteria (Bickel et al., 1960; Cornish and Page, 1995; Münzinger et al., 1999). The mesylate salt of the trishydroxamate siderophore DFOB was purchased from Sigma Aldrich and used without any further purification. Both rhizoferrin (Rhiz; $\alpha$-hydroxycarboxylate siderophore) and protochelin (Proto; a triscatecholamide siderophore) were synthesized by the Duke University Small Molecules Custom Synthesis Facility. The rhizoferrin sample used in this study is a racemic mixture of both naturally occurring enantiomers (Drechsel et al., 1992; Münzinger et al., 1999).

The Fe and Mn oxyhydroxides that were used in this study were chosen to represent common oxide and hydroxide minerals. Heterogenite $(\beta-\mathrm{CoOOH})$, although not environmentally common, was chosen as a model for Co found in solid solution in oxyhydroxide minerals and to facilitate comparison with previous studies (Bi et al., 2010). Goethite $(\alpha-\mathrm{FeOOH})$ was synthesized by reacting $1 \mathrm{M} \mathrm{Fe}\left(\mathrm{NO}_{3}\right)_{3}$ solution with $5 \mathrm{M} \mathrm{KOH}$ solution in a $1 \mathrm{~L}$ Erlenmeyer flask (Cornell and Schwertmann, 1996; Schwertmann and Cornell, 2000). After ageing the resulting precipitate for 6 hours, the mixture was centrifuged and washed with DI water five times. The solution was filtered and the solid residue lyophilized until dry (ca. 48 hrs.). The dry solid was disaggregated with a mortar and pestle and stored in a freezer until use.

Manganite $(\gamma-\mathrm{MnOOH})$ was synthesized according to literature methods (Duckworth and Sposito, 2005b; Giovanoli and Luenberger, 1969; McArdell et al., 1998). Solutions of 0.2 M $\mathrm{NH}_{4} \mathrm{OH}, 0.06 \mathrm{M} \mathrm{MnSO}_{4}$, and $30 \% \mathrm{H}_{2} \mathrm{O}_{2}$ were each purged for $1 \mathrm{~h}$ with $\mathrm{N}_{2}$. A $20.4 \mathrm{~mL}$ aliquot of $\mathrm{N}_{2}$-purged $30 \% \mathrm{H}_{2} \mathrm{O}_{2}$ was added to $1 \mathrm{~L}$ of continuously stirred $\mathrm{MnSO}_{4}$ solution. After stirring for 15 minutes, $300 \mathrm{~mL}$ of $\mathrm{N}_{2}$-purged $\mathrm{NH}_{4} \mathrm{OH}$ solution was slowly added to the $2 \mathrm{~L}$ flask with vigorous stirring, resulting in the formation of a dark-brown precipitate. The suspension was 
rapidly heated to the boiling point, and then maintained at $98{ }^{\circ} \mathrm{C}$ under reflux with constant stirring for $6 \mathrm{~h}$. The resulting mixture was then filtered while hot and washed with $500 \mathrm{~mL}$ of hot DI water during filtration. The residue was then cold-washed by suspension and sonication in deionized water for $15 \mathrm{~min}$, followed by centrifugation for $15 \mathrm{~min}$ at $\sim 25000 \times g \mathrm{RCF}$. The washing process was repeated five times. The washed solid was then freeze dried for $48 \mathrm{hrs,} \mathrm{after}$ which it was disaggregated with a mortar and pestle, and stored in a freezer until use.

The $\mathrm{CoOOH}$ utilized in this study is the same sample used by Bi et al. (2010), and its synthesis and properties have previously been described.

\subsection{Characterization of Oxyhydroxide Minerals}

Dried $\mathrm{Fe}(\mathrm{III})$ and $\mathrm{Mn}(\mathrm{III})$ oxyhydroxide minerals were characterized to determine morphology, phase, and specific surface area. Samples for transmission electron microscopy (TEM) analysis were prepared by dispersing solid particles in methanol. A drop of suspension was placed onto the surface of a carbon film coated $\mathrm{Cu}$ grid (Ted Pella Scientific). After drying, TEM micrographs of $\mathrm{FeOOH}$ and $\mathrm{MnOOH}$ were collected on a Hitachi HF-2000 transmission electron microscope (TEM). Both minerals exhibited particles with a uniform needle-like shape with average lengths of approximately $700 \mathrm{~nm}$ and $400 \mathrm{~nm}$, respectively (Fig. S1). Powder X-ray diffraction (XRD) patterns of solid samples were collected from $15-95^{\circ} 2 \theta$ with a Rigaku SmartLab X-ray diffractometer equipped with a Co-K $\alpha$ source, which confirmed the mineral phase of synthesized solids as goethite and manganite (Fig. S1). Brunauer-Emmett-Teller (BET) surface area analyses of the three minerals determined by nitrogen adsorption using an Autosorb1-MP surface pore analyzer (Quantachrome Corp.) measured 69 and $49 \mathrm{~m}^{2} \mathrm{~g}$ for FeOOH and 
MnOOH, respectively. Bi et al. (2010) reported a BET surface area of $59.8 \mathrm{~m}^{2} \mathrm{~g}$ for the CoOOH used in this study.

\subsection{Dissolution Experiments}

Dissolution rates and products of metal oxyhydroxides were investigated at $\mathrm{pH}=5-9$ in the absence and presence of siderophores. Batch experiments were utilized to conserve siderophore samples. To maintain a constant $\mathrm{pH}$ for each experiment, $10 \mathrm{mM}$ buffer solutions of acetate (Ac), 2-(N-morpholino)ethanesulfonic acid (MES) and 4-(2-hydroxyethyl)-1piperazineethanesulfonic acid (HEPES) (Arcos Organic), were utilized for $\mathrm{pH}$ 5, 6, and 7-9, respectively. These buffers have previously been shown not to affect DFOB-promoted dissolution of metal oxyhydroxides (Bi et al., 2010; Cheah et al., 2003; Duckworth and Sposito, 2005b); however, no specific effort was made in this study to determine their effect on siderophore-promoted dissolution rates. A solution of $0.1 \mathrm{M} \mathrm{NaCl}$ electrolyte solution with 10 $\mathrm{mM}$ buffer was prepared and an aliquot $(50 \mathrm{~mL})$ was pipetted into an Erlenmeyer flask to which a known mass of siderophore was added (final concentration $=100 \mu \mathrm{M}$ ). For protochelin, this solution was briefly sonicated to help to dissolve the siderophore. Next, $0.03 \mathrm{~g}$ of metal oxyhydroxide was added to $100 \mathrm{~mL}$ of buffer and electrolyte solution, and sonicated for approximately $15 \mathrm{~min}$ to disperse particles. The flask was then wrapped in aluminum foil to exclude stray light, placed into a temperature-controlled water bath maintained at $25^{\circ} \mathrm{C}$ with constant stirring. After allowing the reaction temperature to equilibrate, the solution containing buffer, electrolyte, and siderophore was added to the mineral suspension. For FeOOH, a $2 \mathrm{~mL}$ aliquot was collected using a syringe and immediately filtered using a $0.2 \mu \mathrm{m}$ nitrocellulose filter (Millipore). Subsequent aliquots were taken at 12 hour intervals over a 14 day period. For 
$\mathrm{MnOOH}$, the aliquots were collected periodically over $1 \mathrm{hr}$, whereas samples for $\mathrm{CoOOH}$ were collected at $15 \mathrm{~min}$ intervals up to three hours. At each solution $\mathrm{pH}$, three replicates were conducted for experiments containing DFOB, and two replicates were performed for experiments containing protochelin, rhizoferrin, or no siderophore (control experiments). A biocide (e.g., azide) was not added to discourage microbial growth, but the formation of biofilms was not observed in any of the reaction vessels. Drift in the measured solution $\mathrm{pH}$ was found to be less than 0.4 units in all cases.

The dissolution rates of each metal oxyhydroxide as promoted by siderophores in the presence of oxalate were also determined by using a batch reactor approach. Experiments were conducted by the addition of oxalate to a mineral suspension followed by spiking of the system with a siderophore solution (Reichard et al., 2005). Because the effect of oxalate on FeOOH dissolution rate in the presence of siderophores has been shown to be dependent not only on the concentration of oxalate, but also on the initial duration of exposure to oxalate (Reichard et al., 2007b), the durations of the experiments with different minerals were determined by their relative dissolution rates in the absence of oxalate. Stock solutions of DFOB, rhizoferrin, protochelin, and oxalate were prepared immediately prior to the initiation of the experiments. A solution containing $0.1 \mathrm{M} \mathrm{NaCl}$ electrolyte and $10 \mathrm{mM}$ buffer was prepared. Metal oxyhydroxide $(0.03 \mathrm{~g})$ was added to a volume of the buffered electrolyte solution, and the solution was sonicated for 15 minutes. The flask was then wrapped with aluminum foil and placed into a temperature-controlled water bath maintained at $25^{\circ} \mathrm{C}$ with constant stirring. After allowing the reaction temperature to equilibrate, the buffer and electrolyte solution was spiked with oxalate stock solution, resulting in a final oxalate concentration of $1 \mathrm{mM}$. For FeOOH dissolution experiments containing oxalate, aliquots were collected at $\mathrm{t}=0$ and every 24 hours for 96 hours. 
The remaining mineral suspension was spiked with siderophore stock solution to produce a total concentration of $100 \mu \mathrm{M}$. Following siderophore addition, sample aliquots were collected at 8 hour intervals for up to 12 days. For $\mathrm{MnOOH}$ dissolution experiments containing oxalate, aliquots were collected every five minutes starting a half hour prior to spiking with each siderophore stock solution to provide a final concentration of approximately $100 \mu \mathrm{M}$ siderophore. After spiking, aliquots were collected at $5 \mathrm{~min}$ intervals for $1 \mathrm{~h}$. For $\mathrm{CoOOH}$ dissolution experiments containing oxalate, aliquots were collected every $15 \mathrm{~min}$ for an hour prior to spiking with the siderophore stock solution to provide a final concentration of $100 \mu \mathrm{M}$; after which, aliquots were collected at 15 minute intervals for $3 \mathrm{~h}$. All aliquots were immediately filtered through a $0.2 \mu \mathrm{m}$ nitrocellulose filters. Two replicates were conducted for each experimental condition and experimental control reactions were replicated similarly with oxalate in the absence of siderophores.

\subsection{Determination of Dissolution Products and Rates}

The $\mathrm{pH}$ of each aliquot was measured with a Fisher Scientific XL $25 \mathrm{pH}$ meter. The siderophore-metal complex concentration was measured immediately after sampling by UVvisible spectroscopy. Spectra were measured using an Ocean Optics Jaz UV-visible spectrophotometer to determine the complex concentration. The Beer-Lambert extinction coefficients for each M(III)-siderophore complex that was detected in our experiments is listed in Table S1. The subsample was returned to the original aliquot and stored in the dark at $4^{\circ} \mathrm{C}$ for total dissolved metal analysis. Because of the possible redox instability of Mn(III)- and Co(III)siderophore complexes (Harrington et al., 2012a), spectral measurements were performed within $60 \mathrm{~min}$ of the completion of experiments for all dissolution experiments. Quantification of 
$\mathrm{Fe}(\mathrm{III})$-siderophore complexes, which are generally more redox stable than $\mathrm{Mn}$ (III)- and $\mathrm{Co}(\mathrm{III})$ siderophore complexes, was conducted on a daily basis after sampling. In experiments containing $\mathrm{FeOOH}$ and protochelin at $\mathrm{pH}=8-9$, the $\mathrm{Fe}(\mathrm{III})$-protochelin complex was not quantified because a brown colloid associated with the degradation of dissolved protochelin at alkaline pH (Harrington et al., 2012a) interfered with the spectrophotometric measurement.

The samples were acidified with trace metal grade $\mathrm{HCl}$ and diluted to bring sample concentrations within linear range of a Thermo Scientific iCE 3300 flame atomic absorption spectrometer (FAAS). The total dissolved metal concentration was quantified by FAAS to determine trends in dissolved metal concentration as a function of time.

\subsection{Determination of Dissolution Rates}

In the presence of siderophores and the absence of oxalate, dissolution of metal oxyhydroxides may proceed by proton-promoted $\left(R_{H}\right)$, ligand-promoted $\left(R_{L}\right)$, or reductive dissolution pathways $\left(R_{R}\right)$, all of which may occur simultaneously. As such, the total dissolution rate $\left(R_{T}\right)$ is the sum the rate of dissolution from each pathway:

$$
R_{T}=R_{H}+R_{R}+R_{L}
$$

All three trivalent metals are thought to be insoluble or unstable (with respect to other redox states) over the $\mathrm{pH}$ range of the experiments when not complexed by high-affinity ligands. Additionally, control experiments conducted in the absence of siderophores demonstrate that the proton promoted dissolution rates for $\mathrm{MnOOH}, \mathrm{CoOOH}$, and $\mathrm{FeOOH}$ were negligible at all $\mathrm{pH}$ values $\left(R_{H} \approx 0\right.$; data not shown). Hence, dissolution in the presence of siderophores (Sid) is assumed to occur only by reduction of the metal ion center (reductive dissolution, $R_{R}$, eq. 2) or 
by formation of a complex where the oxidation state of the metal center is retained (ligandpromoted dissolution, $R_{L}$, eq. 3):

$$
\begin{gathered}
\mathrm{M}(\mathrm{III}) \mathrm{OOH}+\mathrm{Sid} \rightarrow \mathrm{M}(\mathrm{II})+\mathrm{Sid}_{\mathrm{ox}} \\
\mathrm{M}(\mathrm{III}) \mathrm{OOH}+\mathrm{Sid} \rightarrow \mathrm{M}(\mathrm{III}) \mathrm{Sid}
\end{gathered}
$$

where reductive dissolution results in concomitant oxidation of the siderophore $\left(\operatorname{Sid}_{\mathrm{ox}}\right)$ (Duckworth and Sposito, 2005b). We note that it is also possible for surface redox reactions to result in metal reduction, followed by rapid reoxidation and complexation of the dissolved metal (Dhungana et al., 2007; Simanova et al., 2010). Because we only measure the formation of complexes spectrophotometrically in solution, we are unable to distinguish this potential dissolution pathway from ligand-promoted dissolution.

In the presence of oxalate $(\mathrm{Ox})$, the surface metal atoms may dissolve by oxalatepromoted and reductive pathways $\left(R_{O x}\right.$, eqs. $\left.4-5\right)$ :

$$
\begin{aligned}
& \mathrm{M}(\mathrm{III}) \mathrm{OOH}+3 \mathrm{Ox} \rightarrow \mathrm{M}(\mathrm{III})(\mathrm{Ox})_{3} \\
& 2 \mathrm{M}(\mathrm{III}) \mathrm{OOH}+\mathrm{Ox} \rightarrow \mathrm{M}^{2+}+2 \mathrm{CO}_{3}{ }^{2-}
\end{aligned}
$$

Whereas $\mathrm{Fe}(\mathrm{III})$ minerals may dissolve by both eq. 4 and 5 depending on the environmental conditions (Martin, 2005), eq. 5 is expected to be predominant for MnOOH (Stone, 1987; Xyla et al., 1992). In addition to dissolution via eq. $2-5$, in the presence of siderophores and oxalate there may also be a "synergistic effect", where the dissolution rate is promoted beyond the sum of the individual dissolution rates in the corresponding single component systems (Cervini-Silva and Sposito, 2002; Cheah et al., 2003; Reichard et al., 2007a; Wolff-Boenisch and Traina, 2007b).

For all experiments, plots of both metal-siderophore complex (when detected) and total metal concentration initially increased monotonically as the experiment progressed (Fig. S2-S4). 
To calculate initial dissolution rates in single ligand systems, linear least-square regression analysis was performed on the first $5-10$ points, with the duration chosen by picking the maximum number of linear points, as judged by changes to the regression coefficient $\left(R^{2}>\right.$ 0.85); the overall dissolution rates were then calculated and tested at a $95 \%$ confidence interval, which was used to estimate error. For experiments containing oxalate (Fig. S5), $[\mathrm{Fe}]_{\mathrm{T}}$ (total iron concentration) reached a steady level in the presence of oxalate, followed by a rapid increase upon the addition of siderophore, consistent with previous studies that have used similar methodology (Reichard et al., 2005; Reichard et al., 2007a; Reichard et al., 2007b). The total dissolution rates $\left(R_{\text {Sid-Ox }}\right)$ of the metal oxyhydroxides by siderophores in the presence of oxalic acid were also calculated and tested at a $95 \%$ confidence interval by performing linear regression analysis on the first 3-5 points after siderophore addition, with $R^{2}>0.80$ for these regressions.

\section{Results and Discussion}

\subsection{Trends in Siderophore-promoted Dissolution Rates for Metal Oxyhydroxides.}

The siderophore-promoted total dissolution rates of $\mathrm{FeOOH}, \mathrm{MnOOH}$, and $\mathrm{CoOOH}$ in the presence of DFOB, rhizoferrin, and protochelin are shown in Fig. 2A-C and Table 1. The total dissolution rates of $\mathrm{CoOOH}$ and $\mathrm{MnOOH}$ at all $\mathrm{pH}$ values were faster than those observed for $\mathrm{FeOOH}$. For $\mathrm{MnOOH}$ and $\mathrm{CoOOH}$, dissolution rates decreased with increasing $\mathrm{pH}$ in the presence of all three siderophores. In contrast, $\mathrm{FeOOH}$ dissolution rates were $\mathrm{pH}$-independent for DFOB and rhizoferrin but increased with increasing $\mathrm{pH}$ for protochelin. Observed dissolution rates in the presence of protochelin for each mineral were greater than those observed in the presence of $\mathrm{DFOB}$ and rhizoferrin at all $\mathrm{pH}$ values, with the exception of $\mathrm{FeOOH}$ at $\mathrm{pH}=5$. 
It has been previously noted that $\mathrm{CoOOH}$ and several $\mathrm{Mn}$ oxyhydroxide and oxide minerals dissolve more rapidly than Fe oxyhydroxide and oxide minerals in the presence of the trishydroxamate siderophore DFOB (Bi et al., 2010; Duckworth et al., 2009a). Our results with protochelin and rhizoferrin also follow this trend. Because the siderophores utilized in this study incorporate the range of common siderophore moieties, the results suggest that the observed siderophore-promoted dissolution rates for $\mathrm{Mn}(\mathrm{III})$ and $\mathrm{Co}(\mathrm{III})$ oxyhydroxides may generally exceed those of Fe(III) minerals.

\subsection{Siderophore-promoted Dissolution of FeOOH.}

Figure $2 \mathrm{~A}$ shows the initial siderophore-promoted dissolution rates of $\mathrm{FeOOH}$ at $25{ }^{\circ} \mathrm{C}$. In all cases, the observed total dissolved metal concentration did not exceed the total siderophore concentration, and Fe(III)-siderophore complexes were detected spectrophotometrically at all $\mathrm{pH}$ values (see Fig. S2A-C). For all situations where Fe(III)-siderophore complexes were quantified, the total dissolution rates and ligand-promoted dissolution rates are within experimental error, indicating a predominantly ligand-promoted dissolution mechanism, which is consent with previous studies (Cervini-Silva, 2008; Cocozza et al., 2002; Kraemer et al., 1999; Lloyd, 1999; Wolff-Boenisch and Traina, 2007b).

Observed concentrations of $[\mathrm{Fe}]_{\mathrm{T}}$ and $\mathrm{Fe}(\mathrm{III})$-siderophore complexes initially increase linearly and reach a steady maximum (Fig. S2A-C). For DFOB, this maximum value is $>80 \mu \mathrm{M}$ in all cases, suggesting a reaction stoichiometry between Fe and DFOB that approaches unity. In contrast, the maximum $[\mathrm{Fe}]_{\mathrm{T}}$ values for rhizoferrin are $<70 \mu \mathrm{M}$, suggesting a significantly lower reaction stoichiometry despite the fact that Fe(III)-rhizoferrin is known to form a 1:1 complex (Carrano et al., 1996; Harrington et al., 2012b). For protochelin, the maximum $[\mathrm{Fe}]_{\mathrm{T}}$ values 
range from $15-25 \mu \mathrm{M}$, which may reflect the limited solubility of the neutral $\mathrm{H}_{6}$ Proto and $\mathrm{Fe}(\mathrm{III}) \mathrm{H}_{3}$ Proto species that form at $\mathrm{pH}<7$ or the instability of deprotonated Proto species that form at $\mathrm{pH}>7$ (Harrington et al., 2012b).

The DFOB-promoted dissolution rates measured in this study are significantly higher than the reported surface area-normalized dissolution rates, which vary from $7.3 \times 10^{-13}$ to $2.5 \times$ $10^{-12} \mathrm{~mol} \mathrm{~m} \mathrm{~s}^{-2}$ for DFOB-promoted dissolution of FeOOH. Although it is not completely clear why the rates in this study are higher than those previously reported, it is possibly related to the experimental conditions of the reported rates. The rates reported in this work are initial dissolution rates derived from batch experiments, whereas most literature rates are steady-state rates derived from continuous flow experiments. Initial dissolution rates may reflect contributions from high-energy sites (MacInnis and Brantley, 1992) and commonly exceed steady-state dissolution rates (Duckworth and Sposito, 2005b; Kraemer, 2004). When compared to initial DFOB-promoted FeOOH dissolution rates derived from batch experiments (Table S2), our rates are approximately an order of magnitude greater than literature rates (Carrano et al., 1996; Lloyd, 1999; Neubauer et al., 2002; Wolff-Boenisch and Traina, 2007b) determined at similar DFOB concentrations (Table S2). We do not have an explanation for this discrepancy between our dissolution rates and those in the literature, although differences in experimental conditions (solids loading, ionic strength, concentration, etc.) may account for some variation in rates. Our results for protochelin at $\mathrm{pH}=6$ agree well with initial $\mathrm{FeOOH}$ dissolution rates promoted by enterobactin, which is also a triscatecholate siderophore (Wolff-Boenisch and Traina, 2007b).

It has previously been reported that dissolution rates trend with complex stability constants $(\beta)$ for a group of structurally homologous DFOB derivatives (Cervini-Silva, 2008). 
This trend is also evident in our data, as the Fe(III)Proto ${ }^{3-}$ complex stability constant $(I=0)$ of $\beta$ $=10^{48.6}$ (Duhme et al., 1997) exceed those for $\mathrm{Fe}(\mathrm{III}) \mathrm{HDFOB}^{+}\left(\beta=10^{32.0}\right)$ and $\mathrm{Fe}(\mathrm{III}) \mathrm{Rhiz}^{3-}(\beta=$ $10^{25.3}$ ) (Carrano et al., 1996; Schwarzenbach and Schwarzenbach, 1963). A plot (Fig. 3) of initial dissolution rates for $\mathrm{FeOOH}$ derived from batch reactions with siderophores from our study and from the literature (Table S2) against literature stability constants demonstrates a positive correlation $\left(R^{2}=0.70 ; p<0.05\right)$. The trend, which extends a previous analysis (Cervini-Silva, 2008) to a wider range of structures and stability constants, suggests that siderophore-promoted dissolution processes may be related to mechanisms of complex formation, and that the siderophore-promoted dissolution rate of $\mathrm{FeOOH}$ may be estimated from the ligand-metal stability constant.

\subsection{Siderophore-promoted Dissolution of $\mathrm{CoOOH}$ and $\mathrm{MnOOH}$}

Dissolution rates of $\mathrm{CoOOH}$ and $\mathrm{MnOOH}$ in the presence of siderophores are shown as a function of $\mathrm{pH}$ in Fig. 2B-C and Table 1. Dissolution rates generally decreased with increasing $\mathrm{pH}$ for all siderophores. The rates for protochelin exceed those of DFOB and rhizoferrin, with the greatest differences observed at $\mathrm{pH} \leq 7$. In all cases except DFOB-promoted dissolution at alkaline $\mathrm{pH}$ (for $\mathrm{MnOOH}, \mathrm{pH} \geq 7$; for $\mathrm{CoOOH}, \mathrm{pH} \geq 8$ ), no metal siderophore complexes were detected spectrophotometrically, suggesting that dissolution occurs exclusively by a reductive pathway (Fig. S3-S4). For DFOB, both pH-dependent trends in and values of dissolution rates agree well with those of previous workers, who reported dissolution rates of $0.20-1.7 \times 10^{-9} \mathrm{~mol}$ $\mathrm{m}^{-2} \mathrm{~s}^{-1}$ for $\mathrm{MnOOH}$ (Duckworth and Sposito, 2005b) and $0.55-2.7 \times 10^{-9} \mathrm{~mol} \mathrm{~m}^{-2} \mathrm{~s}^{-1}$ for $\mathrm{CoOOH}$ (Bi et al., 2010) at $\mathrm{pH}=5-9$. 
For $\mathrm{MnOOH}$ and $\mathrm{CoOOH}$, reaction stoichiometries were highly variable for different siderophores. For DFOB, maximum $[\mathrm{Co}]_{\mathrm{T}}$ and $[\mathrm{Mn}]_{\mathrm{T}}$ values at low $\mathrm{pH}$ were approximately 3-4fold higher than the initial DFOB concentration but decreased to a value near unity with increasing $\mathrm{pH}$, consistent with previous results studying the DFOB-promoted dissolution of $\mathrm{CoOOH}$ and $\mathrm{MnOOH}$ (Bi et al., 2010; Duckworth and Sposito, 2005b). For protochelin, a very redox active siderophore (Harrington et al., 2012a), ratios of maximum $[\mathrm{Co}]_{\mathrm{T}}$ and $[\mathrm{Mn}]_{\mathrm{T}}$ values to initial protochelin concentrations varied from $\sim 1-13$ and decreased monotonically with increasing $\mathrm{pH}$. Interestingly, ratios of maximum $[\mathrm{Co}]_{\mathrm{T}}$ and $[\mathrm{Mn}]_{\mathrm{T}}$ values to initial rhizoferrin concentrations were less than unity and varied from $\sim 0.25-0.75$, similar to stoichiometry observed for rhizoferrin-promoted $\mathrm{FeOOH}$ dissolution. These results, coupled with the dissolution rates, indicate significant variation in reactivity of siderophores with redox-active mineral surfaces.

Only reductive dissolution is observed for protochelin- and rhizoferrin-promoted dissolution of $\mathrm{CoOOH}$ and $\mathrm{MnOOH}$. Previous work has shown that $\mathrm{Co}(\mathrm{III})$-protochelin complexes are unstable at all $\mathrm{pH}$ values, and $\mathrm{Mn}$ (III)-protochelin complexes are only transiently stable at alkaline $\mathrm{pH}$ (Harrington et al., 2012a). It is thus not surprising that protochelin dissolved both $\mathrm{CoOOH}$ and $\mathrm{MnOOH}$ solely by reductive pathways. It is more surprising that rhizoferrin only undergoes reductive dissolution with $\mathrm{CoOOH}$ and $\mathrm{MnOOH}$. Although previous reports of attempts to produce a Co(III)-rhizoferrin complex were unsuccessful (Carrano et al., 1996), a Co- rhizoferrin complex that was synthesized by oxidation of $\mathrm{Co}$ (II) with $\mathrm{H}_{2} \mathrm{O}_{2}$ was found by extended X-ray absorption fine structure (EXAFS) spectroscopy to be structurally consistent with Co(III)Rhiz ${ }^{3-}$ (Fig. S6 and Table S3) and determined by potentiometric titration (Fig. S7) to have a stability constant of $\log \beta=38.9$ at $I=0$. For $\mathrm{MnOOH}$, rhizoferrin has been shown to form 
a stable complex with $\mathrm{Mn}(\mathrm{III})$ at alkaline $\mathrm{pH}$ (Harrington et al., 2012b). In addition, high concentrations of citrate, an $\alpha$-hydroxycarboxylate ligand, have been shown to promote dissolution of $\mathrm{MnOOH}$ (feitknechtite with some hausmannite impurity) at $\mathrm{pH} \geq 7$ by both reductive and non-reductive processes (Klewicki and Morgan, 1999). It is possible that a higher concentration of rhizoferrin may produce $\mathrm{Mn}(\mathrm{III}) \mathrm{Rhiz}^{3-}$ or $\mathrm{Co}(\mathrm{III}) \mathrm{Rhiz}^{3-}$ complexes at alkaline $\mathrm{pH}$, although we did not test this hypothesis.

\subsection{Siderophore-promoted Dissolution Rates of Metal Oxyhydroxides in the Presence of} Oxalate.

The dissolution rates of $\mathrm{FeOOH}$ in the presence of oxalate and siderophores are shown in Fig. 4A and Table 2. At $\mathrm{pH}=6$, DFOB in the presence of oxalate exhibits an $\sim 4$-fold enhancement of the sum of both the DFOB- and oxalate-promoted dissolution rates at corresponding conditions, which is roughly consistent with literature results (Cheah et al., 2003; Reichard et al., 2007a). At $\mathrm{pH}=8$, the rates corresponding to the reaction with DFOB in the presence of oxalate are equal to the sum of the oxalate- and siderophore-promoted rates within experimental error. In the presence of oxalate, the dissolution of $\mathrm{FeOOH}$ by protochelin is greatly enhanced compared to the sum of the dissolution rate of each ligand in the system, with dissolution increasing by a factor of approximately 7 at $\mathrm{pH}=6$; a 2.5 -fold enhancement is

observed at $\mathrm{pH}=8$. However, for rhizoferrin at $\mathrm{pH}=6$ and 8 , dissolution rates are equal to the sum of the oxalate- and the rhizoferrin-promoted rates within experimental error, indicating a lack of a synergistic effect on dissolution.

The synergistic effects of oxalate on siderophore-promoted dissolution result from oxalate acting as an iron shuttle that delivers Fe(III) to dissolved siderophores, with detachment 
of a labile pool of Fe(III)-oxalate surface complexes favored by the presence of the siderophore (Loring et al., 2008; Reichard et al., 2007a; Reichard et al., 2007b). This conceptual model may be applied to assist with the interpretation of our results. In our results, the extent to which the dissolution rate is promoted depends on the solution $\mathrm{pH}$ as well as the stability constant of the $\mathrm{Fe}(\mathrm{III})$-siderophore complex. At $\mathrm{pH}=6$, dissolution rates trend with the stability constant of the siderophore. The stability constant of the trisoxalato-Fe(III) complex is $\log \beta=30.75$ (Mollar et al., 1991). Although this stability constant is > 10 orders of magnitude lower than that of protochelin, it is similar in magnitude to that of DFOB and exceeds that of rhizoferrin by several orders of magnitude. This suggests that at high concentrations of oxalate, trisoxalto-Fe(III) complexes may persist transiently in solution containing DFOB (as noted by Cheah et al. (2003) in UV-visible measurements), slowing the synergistic process. In addition, it suggests that it is not thermodynamically favorable for rhizoferrin to remove Fe(III) from trisoxalato complexes, explaining the lack of a synergistic effect on total dissolution rates in the presence of rhizoferrin and oxalate. At $\mathrm{pH}=8$, the sorption of oxalate onto $\mathrm{FeOOH}$ has been shown to be very weak, with only low surface concentrations observed (Eick et al., 1999; Mesuere and Fish, 1992). If we assume that the presence of siderophores does not markedly enhance the adsorption of oxalate (Reichard et al., 2007a), the absence of labile adsorbed oxalate species at $\mathrm{pH}=8$ is consistent with the lack of an effect on the dissolution rates of FeOOH by DFOB and rhizoferrin, and marked reduction of its effect on the dissolution rate of protochelin.

As compared to $\mathrm{FeOOH}$, oxalate exhibited a smaller impact on the siderophore-promoted $\mathrm{CoOOH}$ and $\mathrm{MnOOH}$ dissolution rates (Table 2). Protochelin increased dissolution rates by approximately a factor of two for $\mathrm{MnOOH}$ at $\mathrm{pH}=6$ and for $\mathrm{CoOOH}$ at $\mathrm{pH}=8$; however, no increase in rate was observed for $\mathrm{MnOOH}$ at $\mathrm{pH}=8$, and a decrease in the dissolution rate 
occurred for $\mathrm{CoOOH}$ at $\mathrm{pH}=6$. Similarly, dissolution rates in the presence of oxalate and DFOB or rhizoferrin were not enhanced as compared to the sum of the single-ligand systems. Although the studies use different Mn minerals with different average Mn oxidation numbers, this result is somewhat surprising because Saal and Duckworth (2010) noted a 2-3 fold increase in reductive dissolution rates for $\mathrm{Mn}(\mathrm{IV}) \mathrm{O}_{2}$ in the presence of oxalate. It should be noted that, in addition to the siderophore, oxalate may promote reductive dissolution of Mn oxides (eq. 5) (Stone, 1987; Xyla et al., 1992), and it is possible that the multi-ligand effects, such as the synergistic effect of oxalate and siderophore on ligand-promoted $\mathrm{FeOOH}$ dissolution, may function by differing reaction mechanisms for ligands which promote reductive dissolution. However, more studies of reductive dissolution in multi-ligand systems are needed to better understand these effects.

\section{Summary and Conclusion}

This paper described the dissolution rates and mechanisms of $\mathrm{Fe}(\mathrm{III}), \mathrm{Mn}(\mathrm{III})$, and $\mathrm{Co}(\mathrm{III})$ oxyhydroxides promoted by siderophores with a variety of metal-binding moieties in the presence and absence of oxalate. By incorporating experimental dissolution rates of $\mathrm{FeOOH}$ at $\mathrm{pH}=6$ with literature values of $\mathrm{Fe}(\mathrm{III})$ stability constants, a correlation between mineral dissolution kinetics and complex thermodynamics was demonstrated, extending a previous result derived for a small set of DFOB-derivatives (Cervini-Silva, 2008). In general, siderophorepromoted dissolution rates followed the order $\mathrm{MnOOH}>\mathrm{CoOOH}>\mathrm{FeOOH}$ (Fig. 5), which is consistent with previous results obtained for DFOB. These results extend prior results obtained with DFOB to siderophores comprised of differing functional groups, filling a significant knowledge gap in the literature and allowing us to better estimate the reactivity of siderophores in the environment. If we assume that the range of siderophore moieties used in this study spans 
most of the reactivity of bacterial siderophores with specific metal oxyhydroxides, we can estimate that in the presence of siderophores $(100 \mu \mathrm{M})$, total siderophore-promoted dissolution rates for $\mathrm{MnOOH}, \mathrm{CoOOH}$, and $\mathrm{FeOOH}$ are in the range of $4 \times 10^{-8}-6 \times 10^{-10} \mathrm{~mol} \mathrm{~m}^{-2} \mathrm{~s}^{-1}, 3 \times$ $10^{-8}-4 \times 10^{-11} \mathrm{~mol} \mathrm{~m}^{-2} \mathrm{~s}^{-1}$, and $4 \times 10^{-11}-3 \times 10^{-12} \mathrm{~mol} \mathrm{~m}^{-2} \mathrm{~s}^{-1}$, respectively. This suggests that, depending on their relative environmental abundance, Co and $\mathrm{Mn}$, whose dissolution rates exceed those for Fe by up to 4 orders of magnitude, may compete with Fe for a limited pool of siderophores during siderophore-promoted dissolution of minerals in soils, sediments, and other marine and terrestrial environments.

Siderophores may promote dissolution via ligand promoted or reductive dissolution pathways. For $\mathrm{FeOOH}$, dissolution by all three siderophores results exclusively in the production of $\mathrm{Fe}(\mathrm{III})$-siderophore complexes. In contrast to results with $\mathrm{FeOOH}$, reductive dissolution, resulting in divalent $\mathrm{Co}(\mathrm{II})$ and $\mathrm{Mn}(\mathrm{II})$ metal ions, was the dominant reaction for $\mathrm{MnOOH}$ and $\mathrm{CoOOH}$ at all solution $\mathrm{pH}$ values for rhizoferrin and protochelin and for DFOB at circumneutral to acidic $\mathrm{pH}$. This observation suggests that the dissolution of metal oxyhydroxides may not be a significant source of $\mathrm{Mn}(\mathrm{III})$ - or $\mathrm{Co}(\mathrm{III})$ - complexes in the environment. In addition, because siderophores undergo concomitant oxidation during reduction of metal ions, the rapid reaction of siderophores with these minerals may be a significant sink for siderophores in soils, sediments, and aqueous environments.

Our results may help to shed light on microbial metal solubilization and uptake strategies. Siderophores are not produced in isolation but often in concert with low molecular mass organic acids. In principle, the presence of oxalate may enhance, inhibit, or have no effect on siderophore-promoted dissolution rates. In general, dissolution rates in the presence of oxalate and siderophores were enhanced (as compared to single-ligand systems) for $\mathrm{FeOOH}$ to a greater 
extent than for $\mathrm{CoOOH}$ and $\mathrm{MnOOH}$. For $\mathrm{FeOOH}$, the presence of oxalate resulted in largest increase in rate for protochelin-promoted dissolution. Because protochelin is subject to degradation at $\mathrm{pH} \leq 7$ (Harrington et al., 2012a), small organic acids increase dissolution rates relative to the lifetime of protochelin in alkaline soils. It has been previously suggested that timed exudation of siderophores with organic acids may be part of a biological strategy to maximize iron solubilization (Reichard et al., 2007a). Our observations lead to us to suggest that the exudation of low molecular mass acids in concert with siderophores may be part of a cohesive biological strategy that provides additional benefits, including maximizing the effectiveness of short-lived siderophores in the environment, protecting siderophores from redox reactivity at surfaces (by delivering metals to dissolved species), and specifically increasing the solubilization of targeted metals (e.g., Fe(III)) that may be bound in complicated, multimetalbearing mixtures of solid phases.

Acknowledgements. We are grateful for support received from the National Science Foundation Geobiology and Low-Temperature Geochemistry Program (award number EAR-0921313). We thank Jeff Maske, Erik Nelson, and Matthew Lattimer for help during data collection at the synchrotron. Portions of this research were carried out at the Stanford Synchrotron Radiation Lightsource, a Directorate of SLAC National Accelerator Laboratory and an Office of Science User Facility operated for the U.S. Department of Energy Office of Science by Stanford University. The SSRL Structural Molecular Biology Program is supported by the DOE Office of Biological and Environmental Research, and by the National Institutes of Health, National Institute of General Medical Sciences (including P41GM103393). The contents of this 
publication are solely the responsibility of the authors and do not necessarily represent the official views of NIGMS, NCRR or NIH.

APPENDIX A. Supplementary data associated with this article can be found in the online version, at doi:XXXX 


\section{References}

Adriano, D.C., 2001. Trace Elements in Terrestrial Environments, 2nd ed. Springer, New York.

Albrecht-Gary, A.-M., Crumbliss, A.L., 1998. Coordination chemistry of siderophores: Thermodynamic and kinetics of iron chelation and release. Metal Ions Bio. Syst. 35, 239-327.

Anderegg, G., L'Eplattenier, F., Schwarzenbach, G., 1963. Hydroxamatkomplexe II. Die anwendung der pH-methode. Hel. Chim. Acta 46, 1400-1408.

Bi, Y.Q., Hesterberg, D.L., Duckworth, O.W., 2010. Siderophore-promoted dissolution of cobalt from hydroxide minerals. Geochim. Cosmochim. Acta 74, 2915-2925.

Bickel, H., Bosshardt, R., Gaumann, E., Reusser, P., Vischer, E., Voser, W., Wettstein, A., Zahner, H., 1960. Stoffwechselprodukte von actinomyceten .26. Uber die isolierung und charakterisierung der ferrioxamine a-f, neuer wuchsstoffe der sideramin-gruppe. Helv. Chim. Acta 43, 2118-2128.

Carrano, C.J., Drechsel, H., Kaiser, D., Jung, G., Matzanke, B., Winkelmann, G., Rochel, N., Albrecht-Gary, A.M., 1996. Coordination chemistry of the carboxylate type siderophore rhizoferrin: The iron(III) complex and its metal analogues. Inorg. Chem. 35, 6429-6436.

Carrasco, N., Kretzschmar, R., Pesch, M.-L., Kraemer, S.M., 2007. Low concentrations of surfactants enhance siderophore-promoted dissolution of goethite. Environ. Sci. Technol. 41, 3633-3638.

Cervini-Silva, J., 2008. Adsorption of trihydroxamate and catecholate siderophores on $\alpha$-iron (hydr)oxides and their dissolution at pH 3.0 to 6.0. Soil Sci. Soc. Am. J. 72, 1557-1562.

Cervini-Silva, J., Kearns, J., Banfield, J., 2012. Steady-state dissolution kinetics of mineral ferric phosphate in the presence of desferrioxamine- $\mathrm{B}$ and oxalate ligands at $\mathrm{pH}=4-6$ and $\mathrm{T}=24 \pm 0.6$ degrees C. Chem. Geol. 320, 1-8.

Cervini-Silva, J., Sposito, G., 2002. Steady-state dissolution kinetics of aluminum-goethite in the presence of desferrioxamine-B and oxalate ligands. Environ. Sci. Technol. 36, 337-342.

Cheah, S.F., Kraemer, S.M., Cervini-Silva, J., Sposito, G., 2003. Steady-state dissolution kinetics of goethite in the presence of desferrioxamine B and oxalate ligands: Implications for the microbial acquisition of iron. Chem. Geol. 198, 63-75.

Cocozza, C., Tsao, C.C.G., Cheah, S.F., Kraemer, S.M., Raymond, K.N., Miano, T.M., Sposito, G., 2002. Temperature dependence of goethite dissolution promoted by trihydroxamate siderophores. Geochim. Cosmochim. Acta 66, 431-438.

Cornejo-Garrido, H., Fernandez-Lomelin, P., Guzman, J., Cervini-Silva, J., 2008. Dissolution of arsenopyrite (FeAsS) and galena $(\mathrm{PbS})$ in the presence of desferrioxamine-B at $\mathrm{pH}$ 5. Geochim. Cosmochim. Acta 72, 2754-2766. 
Cornell, R.M., Schwertmann, U., 1996. The Iron Oxides. VCH Publishers, Inc., New York.

Cornish, A.S., Page, W.J., 1995. Production of the tricatecholate siderophore protochelin by Azotobacter vinelandii. Biometals 8, 332-338.

Crumbliss, A.L., Harrington, J.M., 2009. Iron Sequestration by small molecules: Thermodynamic and kinetic studies of natural siderophores and synthetic model Compounds. Advances in Inorganic Chemistry, Vol 61: Metal Ion Controlled Reactivity 61, 179-250.

Dehner, C.A., Awaya, J.D., Maurice, P.A., DuBois, J.L., 2010. Roles of siderophores, oxalate, and ascorbate in mobilization of iron from hematite by the aerobic bacterium Pseudomonas mendocina. Appl. Environ. Microbiol. 76, 2041-2048.

Dhungana, S., Anthony, C.R., Hersman, L.E., 2007. Ferrihydrite dissolution by pyridine-2,6bis(monothiocarboxylic acid) and hydrolysis products. Geochim. Cosmochim. Acta 71, 56515660 .

Drechsel, H., Jung, G., Winkelmann, G., 1992. Stereochemical characterization of rhizoferrin and identification of its dehydration products. BioMetals 5, 141-148.

Duckworth, O.W., Bargar, J.R., Sposito, G., 2009a. Coupled biogeochemical cycling of iron and manganese as mediated by microbial siderophores. BioMetals 22, 605-613.

Duckworth, O.W., Jarzecki, A.A., Bargar, J.R., Oyerinde, O., Spiro, T.G., Sposito, G., 2009b. An exceptionally stable cobalt(III)-desferrioxamine B complex. Marine Chem. 113, 114-122.

Duckworth, O.W., Sposito, G., 2005a. Siderophore-manganese(III) interactions I. Air-oxidation of manganese(II) promoted by desferrioxamine B. Environ. Sci. Technol. 39, 6037-6044.

Duckworth, O.W., Sposito, G., 2005b. Siderophore-manganese(III) interactions II. Manganite dissolution promoted by desferrioxamine B. Environ. Sci. Technol. 39, 6045-6051.

Duckworth, O.W., Sposito, G., 2007. Siderophore-promoted dissolution of synthetic and biogenic layer-type Mn oxides. Chem. Geol. 242, 497-508.

Duhme, A.K., Hider, R.C., Khodr, H.H., 1997. Synthesis and iron-binding properties of protochelin, the tris(catecholamide) siderophore of Azotobacter vinelandii. Chemische BerichteRecueil 130, 969-973.

Eick, M.J., Peak, J.D., Brady, W.D., 1999. The effect of oxyanions on the oxalate-promoted dissolution of goethite. Soil Sci. Soc. Am. J. 63, 1133-1141.

Frausto da Silva, J.R.R., Williams, R.J.P., 1991. The Biological Chemistry of the Elements. Clarendon Press, Oxford.

Giovanoli, R., Luenberger, U., 1969. Oxidation of manganese oxide hydroxide. Hel. Chim. Acta 58, 2333-2347. 
Haack, E.A., Johnston, C.T., Maurice, P.A., 2008. Mechanisms of siderophore sorption to smectite and siderophore-enhanced release of structural $\mathrm{Fe}^{3+}$. Geochim. Cosmochim. Acta 72, 3293-3586.

Harrington, J.M., Bargar, J.M., Jarzecki, A.A., Sombers, L.A., Roberts, J.G., Duckworth, O.W., 2012a. Trace metal complexation by the triscatecholate siderophore protochelin: structure and stability. BioMetals 25, 393-412.

Harrington, J.M., Crumbliss, A.L., 2009. The redox hypothesis in siderophore-mediated iron uptake. Biometals 22, 679-689.

Harrington, J.M., Parker, D.L., Bargar, J.R., Jarzecki, A.A., Tebo, B.M., Sposito, G., Duckworth, O.W., 2012b. Structural dependence of Mn complexation by siderophores: Donor group dependence on complex stability and reactivity. Geochim. Cosmochim. Acta 88, 106-119.

Hersman, L., Lloyd, T., Sposito, G., 1995. Siderophore-promoted dissolution of hematite. Geochim. Cosmochim. Acta 59, 3327-3330.

Hider, R.C., Kong, X., 2010. Chemistry and biology of siderophores. Nat. Prod. Rep. 27, 637657.

Hou, Z., Whisenhunt, D.W., Xu, J., Raymond, K.N., 1994. Potentiometric, spectrophotometric, and $1 \mathrm{H}$ NMR study of four desferrioxamine B derivatives and their ferric complexes. J. Am. Chem. Soc. 116, 840-846.

Klewicki, J.K., Morgan, J.J., 1999. Dissolution of $\beta$-MnOOH particles by ligand: Pyrophosphate, ethylenediaminetetraacetate, and citrate. Geochim. Cosmochim. Acta 63, 2017-3024.

Kraemer, S.M., 2004. Iron oxide dissolution and solubility in the presence of siderophores. Aquat. Sci. 66, 3-18.

Kraemer, S.M., Cheah, S.F., Zapf, R., Xu, J., Raymond, K.N., Sposito, G., 1999. Effect of hydroxamate siderophores on $\mathrm{Fe}$ release and $\mathrm{Pb}(\mathrm{II})$ adsorption by goethite. Geochim. Cosmochim. Acta 63, 3003-3008.

Kraepiel, A.M.L., Bellenger, J.P., Wichard, T., Morel, F.M.M., 2009. Multiple roles of siderophores in free living nitrogen fixing bacteria. Biometals 22, 573-581.

Liermann, L.J., Guynn, R.L., Anbar, A., Brantley, S.L., 2005. Production of a molybdophore during metal-targeted dissolution of silicates by soil bacteria. Chem. Geol. 220, 285-302.

Liermann, L.J., Kalinowski, B.E., Brantley, S.L., Ferry, J.G., 2000. Role of bacterial siderophores in the dissolution of hornblende. Geochim. Cosmochim. Acta 64, 587-602.

Lloyd, T., 1999. Dissolution of Fe(III) and Mn(III,IV)-(hydr)oxides by desferrioxamine B. California Institute of Technology, Pasadena. 
Loomis, L.D., Raymond, K.N., 1991. Solution equilibria of enterobactin and metal-enterobactin complexes. Inorg. Chem. 30, 906-911.

Loring, J.S., Simanova, A.A., Persson, P., 2008. Highly mobile iron pool from a dissolutionreadsorption process. Langmuir 24, 7054-7057.

MacInnis, I.N., Brantley, S.L., 1992. The role of dislocations and surface morphology in calcite dissolution. Geochim. Cosmochim. Acta 56, 1113-1126.

Marschner, H., Romheld, V., Kissel, M., 1986. Different strategies in higher plants in mobilization and uptake of iron. J. Plant Nutr. 9, 695-713.

Martin, S.T., 2005. Precipitation and dissolution of iron and manganese oxides, in: Grassian, V.H. (Ed.), Environmental Catalysis. Marcel-Dekker, CRC Press, Boca Raton, pp. 61-81.

McArdell, C.S., Stone, A.T., Tian, J., 1998. Reaction of EDTA and related aminocarboxylate chelating agents with $\mathrm{Co}{ }^{\mathrm{III}} \mathrm{OOH}$ (heterogenite) and $\mathrm{Mn}^{\mathrm{III}} \mathrm{OOH}$ (manganite). Environ. Sci. Technol. 32, 2923-2930.

Mesuere, K., Fish, W., 1992. Chromate and oxalate adsorption on goethite. 1. Calibration of surface complexation models. Environ. Sci. Technol. 26, 2357-2364.

Mollar, M., Castro, I., Lloret, F., Julve, M., Faus, J., Latorre, J., 1991. A solution study of complex formation between iron(III) and oxalate in dimethylsulphoxide. Transition Met Chem $16,31-34$.

Münzinger, M., Taraz, K., Budzikiewicz, H., Drechsel, H., Heymann, P., Winkelmann, G., Meyer, J.-M., 1999. S, S-rhizoferrin (enantio-rhizoferrin) - a siderophore of Ralstonia (Pseudomonas) pickettii DSM 6297 - the optical antipode of R, R-rhizoferrin isolated from fungi. BioMetals 12, 189-193.

Murakami, T., Ise, K., Hayakawa, M., Kamei, S., Takagi, S., 1989. Stabilities of metal complexes of mugineic acids and their specific affinities for iron(III). Chem. Lett., 2137-2140.

Neubauer, U., Furrer, G., Schulin, R., 2002. Heavy metal sorption on soil minerals affected by the siderophore desferrioxamine B: the role of Fe(III) (hydr)oxides and dissolved Fe(III). Europ. J. Soil Sci. 53, 45-55.

Parker, D.L., Sposito, G., Tebo, B.M., 2004. Manganese(III) binding to a pyoverdine siderophore produced by a manganese(II)-oxidizing bacterium. Geochim. Cosmochim. Acta 68, 4809-4820.

Peña, J., Duckworth, O.W., Bargar, J.R., Sposito, G., 2007. Dissolution of hausmannite in the presence of the trihydroxamate siderophore desferrioxamine B. Geochim. Cosmochim. Acta 71, 5661-5671.

Reichard, P.U., Kraemer, S.M., Frazier, S.W., Kretzschmar, R., 2005. Goethite dissolution in the presence of phytosiderophores: Rates, mechanisms, and the synergistic effect of oxalate. Plant Soil 276, 115-132. 
Reichard, P.U., Kretzschmar, R., Kraemer, S.M., 2007a. Dissolution mechanisms of goethite in the presence of siderophores and organic acids. Geochim. Cosmochim. Acta 71, 5635-5650.

Reichard, P.U., Kretzschmar, R., Kraemer, S.M., 2007b. Rate laws of steady-state and nonsteady-state ligand-controlled dissolution of goethite. Colloids and Surfaces a-Physicochemical and Engineering Aspects 306, 22-28.

Rosenberg, D.R., Maurice, P.A., 2003. Siderophore adsorption to and dissolution of kaolinite at $\mathrm{pH} 3$ to 7 at $22{ }^{\circ} \mathrm{C}$. Geochim. Cosmochim. Acta 67, 223-229.

Saal, L.B., Duckworth, O.W., 2010. Synergistic dissolution of manganese oxides as promoted by siderophores and small organic acids. Soil Sci. Soc. Am. J. 74, 2032-2038.

Schalk, I.J., Hannauer, M., Braud, A., 2011. New roles for bacterial siderophores in metal transport and tolerance. Environ. Microbiol. 13, 2844-2854.

Schwarzenbach, G., Schwarzenbach, K., 1963. Hydroxamatkomplexe I. Die stabilitat der eisen(III)-komplexe einfacher hydroxamsauren und des ferrioxamins B. Hel. Chim. Acta 46, 1390-1400.

Schwertmann, U., Cornell, R.M., 2000. Iron Oxides in the Laboratory. VCH Publishers, Inc, New York.

Simanova, A.A., Persson, P., Loring, J.S., 2010. Evidence for ligand hydrolysis and Fe(III) reduction in the dissolution of goethite by desferrioxamine-B. Geochim. Cosmochim. Acta 74, 6706-6720.

Stintzi, A., Barnes, C., Xu, L., Raymond, K.N., 2000. Microbial iron transport via a siderophore shuttle: A membrane ion transport paradigm. Proc. Nat. Acad. Sci. USA 97, 10691-10696.

Stone, A.T., 1987. Microbial metabolites and the reductive dissolution of manganese oxides: Oxalate and pyruvate. Geochim. Cosmochim. Acta 51, 919-925.

Watteau, F., Berthelin, J., 1994. Microbial dissolution of iron and aluminum from soil minerals efficiency and specificity of hydroxamate siderophores compared to aliphatic acids. Eur. J. Soil. Biol. 30, 1-9.

Winkelmann, G., 2007. Ecology of siderophores with special reference to the fungi. BioMetals 20, 379-392.

Wolff-Boenisch, D., Traina, S.J., 2007a. The effect of desferrioxamine B on the desorption of $\mathrm{U}(\mathrm{VI})$ from Georgia kaolinite $\mathrm{KGa}-1 \mathrm{~b}$ and its ligand-promoted dissolution at $\mathrm{pH} 6$ and $25{ }^{\circ} \mathrm{C}$. Chem. Geol. 242, 278-287.

Wolff-Boenisch, D., Traina, S.J., 2007b. The effect of desferrioxamine B, enterobactin, oxalic acid, and Na-alginate on the dissolution of uranyl-treated goethite at $\mathrm{pH} 6$ and $25^{\circ} \mathrm{C}$. Chem. Geol. 243, 357-368. 
Xyla, A.G., Sulzberger, B., Luther, G.W., Hering, J.G., Van Cappellen, P., Stumm, W., 1992. Reductive dissolution of manganese(III,IV) (hydr)oxides by oxalate: the effect of $\mathrm{pH}$ and light. Langmuir 8, 95-103. 


\section{Figures.}

Fig. 1. Structures of the siderophores selected for use in this study, which were chosen to span the structural diversity of common binding moieties found in microbial siderophores.

Fig. 2. Average initial ligand-promoted $\left(R_{L}\right)$ (open symbol) and total $\left(R_{T}\right)$ (closed symbols) dissolution rates $\left(\mathrm{mol} \mathrm{m} \mathrm{m}^{-2} \mathrm{~s}^{-1}\right.$ ) for (A) $\mathrm{FeOOH}$, (B) $\mathrm{MnOOH}$, and (C) $\mathrm{CoOOH}$ as promoted by DFOB (black triangles), rhizoferrin (gray squares), and protochelin (black diamonds). Conditions: $0.2 \mathrm{~g} \mathrm{~L}^{-1}$ metal oxyhydroxide; $100 \mu \mathrm{M}$ siderophore; $25^{\circ} \mathrm{C} ; 10$ $\mathrm{mM}$ buffer; $0.1 \mathrm{M} \mathrm{NaCl}$ solution. Error bars represent $95 \%$ confidence intervals.

Fig. 3. Log-log plot of stability constant (Albrecht-Gary and Crumbliss, 1998; Carrano et al., 1996; Duhme et al., 1997; Hou et al., 1994; Loomis and Raymond, 1991; Murakami et al., 1989; Schwarzenbach and Schwarzenbach, 1963) and dissolution rates of $\alpha-\mathrm{FeOOH}$ (squares) as promoted by siderophores used in this study and from literature at $\mathrm{pH}=6$. Open points indicate rates derived from this study. Other dissolution rates (closed points) are collected from experiments (Carrasco et al., 2007; Cervini-Silva, 2008; Cocozza et al., 2002; Neubauer et al., 2002; Wolff-Boenisch and Traina, 2007b) at similar conditions (66-500 $\mu \mathrm{M}$ siderophore, $\mathrm{pH}=6$; Table S2). Ent = enterobactin;

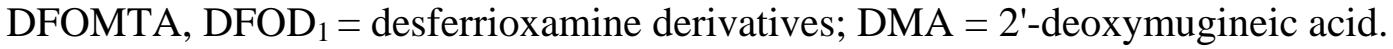

Fig. 4. Average initial total dissolution rates $\left(\mathrm{mol} \mathrm{m}^{-2} \mathrm{~s}^{-1}\right)$ for $(\mathrm{A}) \mathrm{FeOOH}$ in the absence $\left(R_{T}\right.$; closed symbols) and presence of oxalate $\left(R_{\text {Sid-Ox }}\right.$; open symbols $)$ as promoted by $(\mathrm{A})$ DFOB (triangles), (B) protochelin (squares), and (C) rhizoferrin (diamonds). Oxalatepromoted rates $\left(R_{O x}\right)$ in the absence of siderophores are shown as open circles. Conditions: $0.2 \mathrm{~g} \mathrm{~L}^{-1}$ metal oxyhydroxide; 0 or $100 \mu \mathrm{M}$ siderophore; 0 or $1000 \mu \mathrm{M}$ oxalate; $25^{\circ} \mathrm{C} ; 10 \mathrm{mM}$ buffer; $0.1 \mathrm{M} \mathrm{NaCl}$ solution. Error bars represent 95\% confidence intervals.

Fig. 5. Average initial total $\left(R_{T}\right)$ dissolution rates $\left(\mathrm{mol} \mathrm{m}^{-2} \mathrm{~s}^{-1}\right)$ for $\mathrm{FeOOH}$ (orange), $\mathrm{MnOOH}$ (pink), and $\mathrm{CoOOH}$ (green) as promoted by DFOB (triangles), rhizoferrin (diamonds), and protochelin (squares). Shaded areas show the bounds of dissolution rates as promoted by the trishydroxamate, triscatecholate, and $\alpha$-hydroxycarboxylate siderophores in this study. Conditions: $0.2 \mathrm{~g} \mathrm{~L}^{-1}$ metal oxyhydroxide; $100 \mu \mathrm{M}$ siderophore; $25^{\circ} \mathrm{C} ; 10 \mathrm{mM}$ buffer; $0.1 \mathrm{M} \mathrm{NaCl}$ solution. 
Table 1. Average initial total $\left(R_{T}\right)$ and ligand-promoted $\left(R_{L}\right)$ dissolution rates $\left(\mathrm{mol} \mathrm{m}^{-2} \mathrm{~s}^{-1}\right)$ for $\mathrm{FeOOH}, \mathrm{MnOOH}$, and $\mathrm{CoOOH}$ as promoted by $\mathrm{DFOB}$, rhizoferrin, and protochelin. Conditions: $0.2 \mathrm{~g} \mathrm{~L}^{-1}$ metal hydroxide; $100 \mu \mathrm{M}$ siderophore; $25^{\circ} \mathrm{C} ; 10 \mathrm{mM}$ buffer; $0.1 \mathrm{M} \mathrm{NaCl}$ solution. Error bars represent $95 \%$ confidence intervals. Conditions: $0.2 \mathrm{~g} \mathrm{~L}^{-1} \mathrm{FeOOH} ; 100 \mu \mathrm{M}$ siderophore; $25^{\circ} \mathrm{C} ; 10 \mathrm{mM}$ buffer; $0.1 \mathrm{M} \mathrm{NaCl}$. $\mathrm{ND}=$ not detected. $\mathrm{NM}=$ not measured.

\begin{tabular}{ccccccc}
\hline \multicolumn{7}{c}{ total FeOOH dissolution rates $\times 10^{-11}\left(\mathrm{~mol} \mathrm{~m}^{-2} \mathrm{~s}^{-1}\right)$} \\
\hline \multicolumn{2}{c}{ DFOB } & \multicolumn{2}{c}{ Rhizoferrin } & \multicolumn{2}{c}{ Protochelin } \\
\hline $\mathrm{pH}$ & $R_{T}$ & $R_{L}$ & $R_{T}$ & $R_{L}$ & $R_{T}$ & $R_{L}$ \\
\hline 5 & $1.6 \pm 0.4$ & $1.6 \pm 0.3$ & $0.6 \pm 0.1$ & $0.6 \pm 0.1$ & $0.4 \pm 0.2$ & $0.4 \pm 0.2$ \\
6 & $1.3 \pm 0.3$ & $1.3 \pm 0.2$ & $0.4 \pm 0.1$ & $0.6 \pm 0.1$ & $2 \pm 1$ & $1 \pm 2$ \\
7 & $1.3 \pm 0.1$ & $1.3 \pm 0.4$ & $0.4 \pm 0.1$ & $0.5 \pm 0.1$ & $3 \pm 1$ & $2 \pm 1$ \\
8 & $1.2 \pm 0.4$ & $1.2 \pm 0.1$ & $0.4 \pm 0.2$ & $0.5 \pm 0.1$ & $4 \pm 1$ & $\mathrm{NM}$ \\
9 & $1.2 \pm 0.2$ & $1.2 \pm 0.5$ & $0.3 \pm 0.1$ & $0.5 \pm 0.1$ & $3.0 \pm 0.2$ & $\mathrm{NM}$ \\
\hline
\end{tabular}

\begin{tabular}{|c|c|c|c|c|}
\hline \multicolumn{5}{|c|}{ total $\mathrm{MnOOH}$ dissolution rates $\times 10^{-9}\left(\mathrm{~mol} \mathrm{~m}^{-2} \mathrm{~s}^{-1}\right)$} \\
\hline & & & Rhizo & Proto \\
\hline $\mathrm{pH}$ & $R_{T}$ & $R_{L}$ & $R_{T}$ & $R_{T}$ \\
\hline 5 & $10.0 \pm 0.7$ & ND & $4 \pm 1$ & $34 \pm 2$ \\
\hline 6 & $3.0 \pm 0.2$ & ND & $2.2 \pm 0.3$ & $17 \pm 1$ \\
\hline 7 & $1.6 \pm 0.2$ & $1.9 \pm 0.3$ & $1.4 \pm 0.2$ & $13 \pm 3$ \\
\hline 8 & $1.6 \pm 0.2$ & $1.5 \pm 0.3$ & $1.0 \pm 0.1$ & $11 \pm 6$ \\
\hline 9 & $0.80 \pm 0.04$ & $0.8 \pm 0.1$ & $0.6 \pm 0.1$ & $9 \pm 2$ \\
\hline
\end{tabular}

\begin{tabular}{|c|c|c|c|c|}
\hline \multicolumn{5}{|c|}{ total $\mathrm{CoOOH}$ dissolution rates $\times 10^{-9}\left(\mathrm{~mol} \mathrm{~m}^{-2} \mathrm{~s}^{-1}\right)$} \\
\hline & & & Rhizo & Proto \\
\hline $\mathrm{pH}$ & $R_{T}$ & $R_{L}$ & $R_{T}$ & $R_{T}$ \\
\hline 5 & $2.6 \pm 0.1$ & ND & $0.30 \pm 0.04$ & $24 \pm 10$ \\
\hline 6 & $1.6 \pm 0.2$ & ND & $0.20 \pm 0.03$ & $26 \pm 6$ \\
\hline 7 & $1.3 \pm 0.2$ & ND & $0.10 \pm 0.01$ & $8 \pm 1$ \\
\hline 8 & $1.1 \pm 0.1$ & $0.4 \pm 0.2$ & $0.10 \pm 0.01$ & $4 \pm 2$ \\
\hline 9 & $1.0 \pm 0.1$ & $0.9 \pm 0.3$ & $0.04 \pm 0.01$ & $2.0 \pm 0.4$ \\
\hline
\end{tabular}


Table 2. Total siderophore-promoted dissolution rates for $\mathrm{FeOOH}, \mathrm{CoOOH}$, and $\mathrm{MnOOH}$ in the absence $\left(R_{T}\right)$ and presence of oxalate $\left(R_{\text {Sid-Ox }}\right)$. Conditions: $0.2 \mathrm{~g} \mathrm{~L}^{-1}$ metal oxyhydroxide; 0 or $100 \mu \mathrm{M}$ siderophore; 0 or $1000 \mu \mathrm{M}$ oxalate; $25^{\circ} \mathrm{C}$; $10 \mathrm{mM}$ buffer; $0.1 \mathrm{M} \mathrm{NaCl}$.

\begin{tabular}{|c|c|c|c|c|c|c|c|}
\hline \multicolumn{8}{|c|}{ total FeOOH dissolution rates $\times 10^{-11}\left(\mathrm{~mol} \mathrm{~m}^{-2} \mathrm{~s}^{-1}\right)$} \\
\hline & \multicolumn{3}{|c|}{ no oxalate $\left(R_{T}\right)$} & \multirow{2}{*}{$\begin{array}{c}\text { oxalate }\left(R_{O x}\right) \\
\text { oxalate }\end{array}$} & \multicolumn{3}{|c|}{ with oxalate $\left(R_{\text {Sid-Ox }}\right)$} \\
\hline $\mathrm{pH}$ & proto & rhizo & DFOB & & proto & rhizo & DFOB \\
\hline 6 & $2 \pm 1$ & $0.3 \pm 0.1$ & $0.6 \pm 0.2$ & $0.4 \pm 0.3$ & $14 \pm 9$ & $0.3 \pm 0.1$ & $4 \pm 1$ \\
\hline 8 & $4 \pm 1$ & $0.3 \pm 0.1$ & $1.5 \pm 0.2$ & $0.1 \pm 0.1$ & $10 \pm 4$ & $0.3 \pm 0.1$ & $0.7 \pm 0.1$ \\
\hline \multicolumn{8}{|c|}{ total $\mathrm{MnOOH}$ dissolution rates $\times 10^{-9}\left(\mathrm{~mol} \mathrm{~m}^{-2} \mathrm{~s}^{-1}\right)$} \\
\hline & \multicolumn{3}{|c|}{ no oxalate $\left(R_{T}\right)$} & oxalate $\left(R_{O x}\right)$ & \multicolumn{3}{|c|}{ with oxalate $\left(R_{\text {Sid-Ox }}\right)$} \\
\hline $\mathrm{pH}$ & proto & rhizo & DFOB & oxalate & proto & Rhizo & DFOB \\
\hline 6 & $17 \pm 1$ & $2.0 \pm 0.3$ & $3.0 \pm 0.2$ & $0.8 \pm 0.3$ & $27 \pm 6$ & $2.1 \pm 0.3$ & $3.2 \pm 0.2$ \\
\hline 8 & $11 \pm 6$ & $1.0 \pm 0.1$ & $1.6 \pm 0.2$ & $0.3 \pm 0.2$ & $9 \pm 7$ & $1.0 \pm 0.3$ & $1.0 \pm 0.1$ \\
\hline \multicolumn{8}{|c|}{ total $\mathrm{CoOOH}$ dissolution rates $\times 10^{-9}\left(\mathrm{~mol} \mathrm{~m}^{-2} \mathrm{~s}^{-1}\right)$} \\
\hline & \multicolumn{3}{|c|}{ no oxalate $\left(R_{T}\right)$} & oxalate $\left(R_{O x}\right.$ & \multicolumn{3}{|c|}{ with oxalate $\left(R_{\text {Sid-Ox }}\right)$} \\
\hline $\mathrm{pH}$ & proto & rhizo & DFOB & oxalate & proto & rhizo & DFOB \\
\hline 6 & $26 \pm 6$ & $0.2 \pm 0.03$ & $2.0 \pm 0.2$ & $0.2 \pm 0.1$ & $14 \pm 6$ & $0.3 \pm 0.1$ & $1.0 \pm 0.1$ \\
\hline 8 & $4 \pm 2$ & $0.1 \pm 0.01$ & $1.0 \pm 0.1$ & $0.03 \pm 0.02$ & $6 \pm 3$ & $0.10 \pm 0.01$ & $1.0 \pm 0.2$ \\
\hline
\end{tabular}



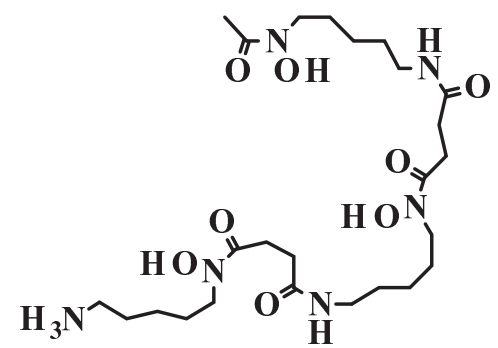

Desferrioxamine B
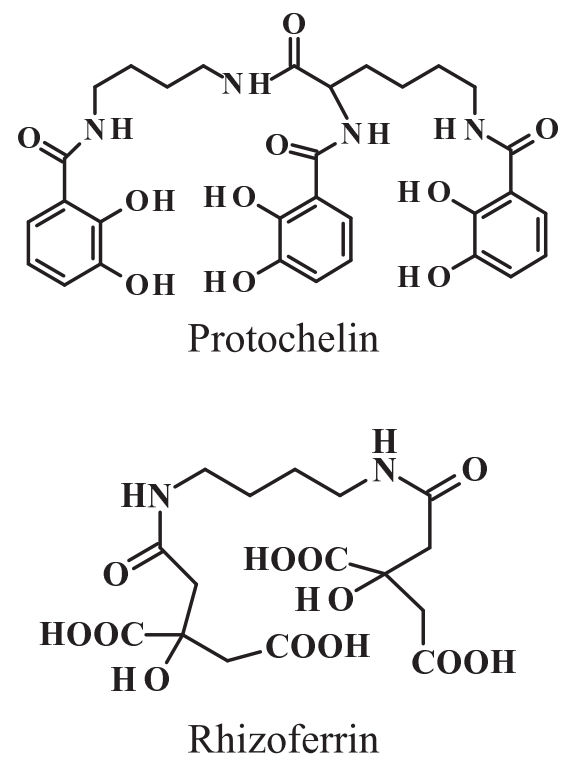

Figure 1. 

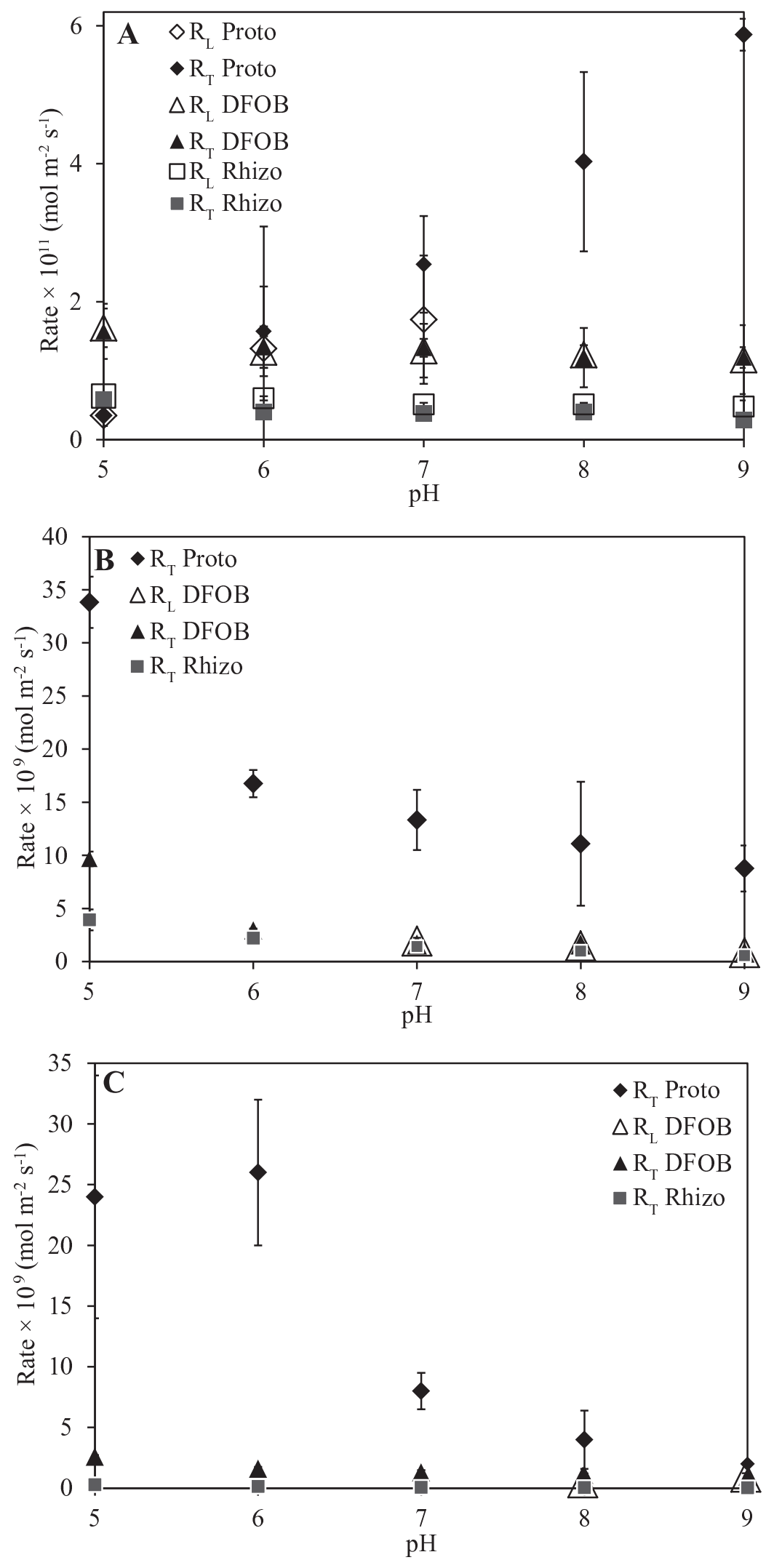

Figure 2. 


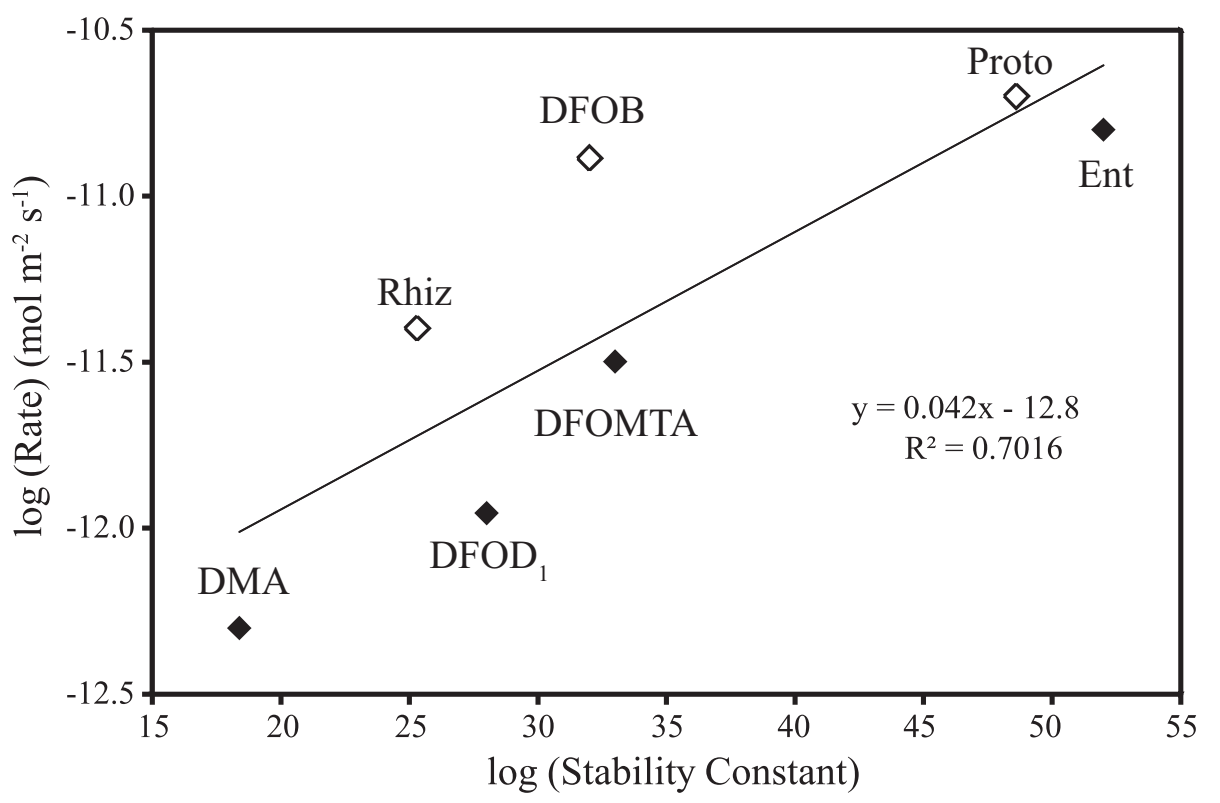

Figure 3. 

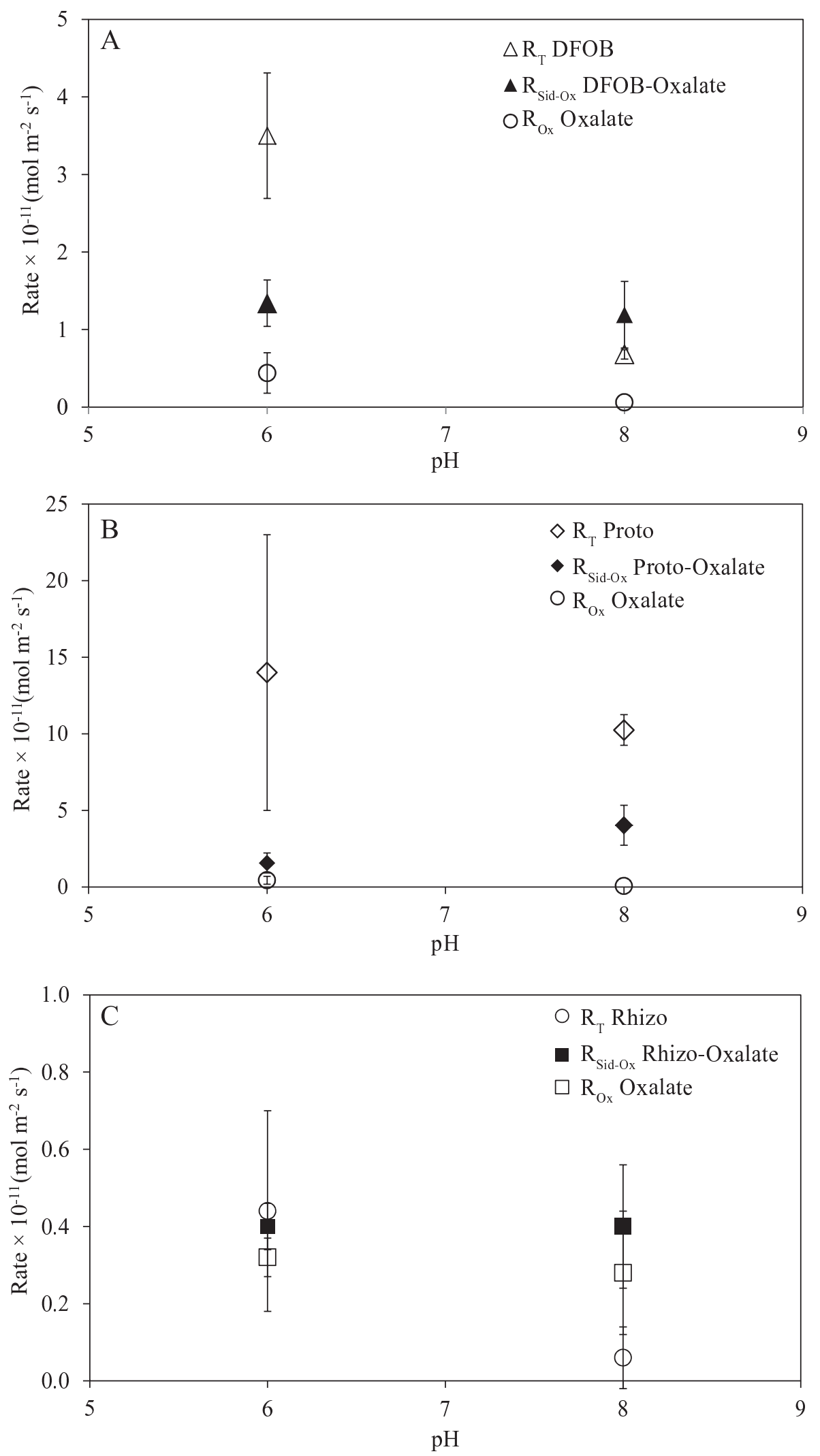

Figure 4. 


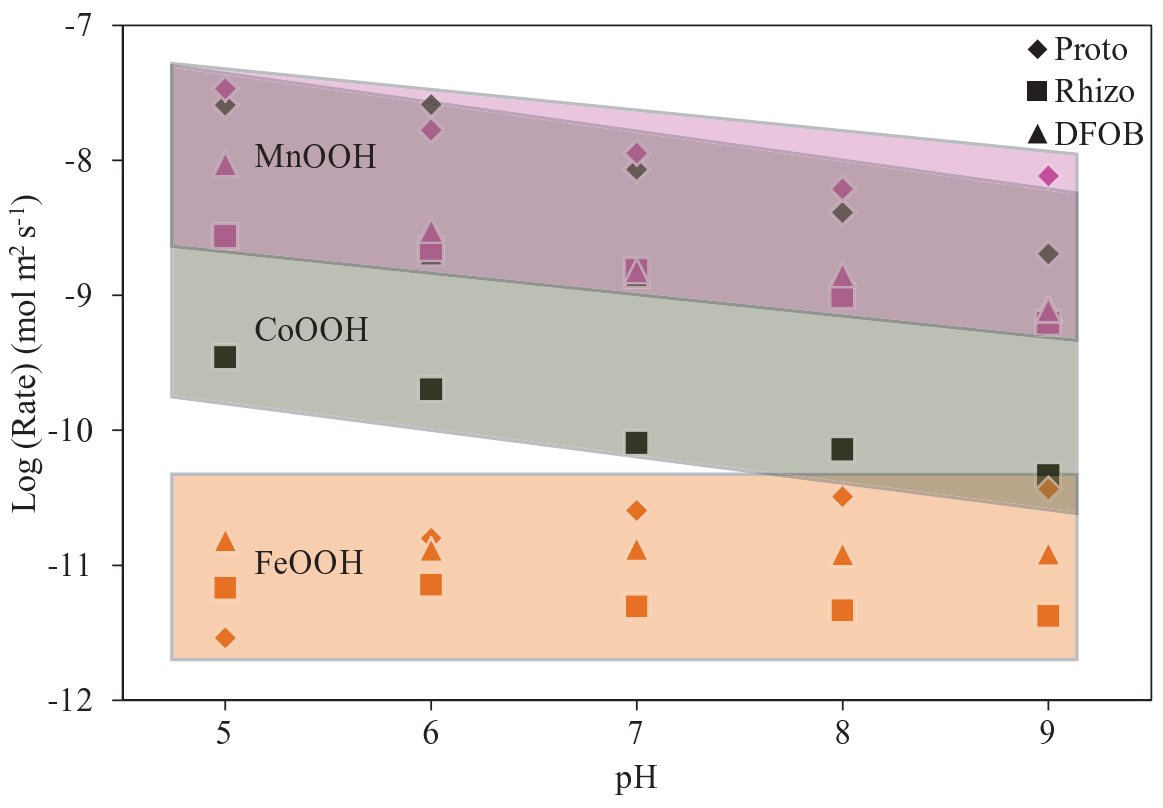

Figure 5. 